\title{
A linguistic analysis of spelling errors in Grade 3 isiXhosa home-language learners
}

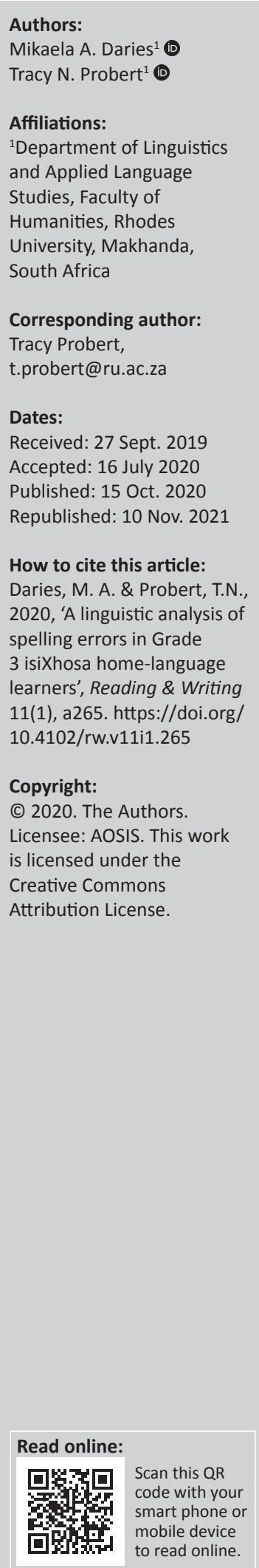

Background: Spelling is a vital component of literacy. This is because spelling includes multiple metalinguistic components, such as phoneme-grapheme awareness, orthographic awareness and morphophonemic knowledge. Despite this, there remains, to date, insufficient literature on spelling in the Southern Bantu languages and, more specifically, in isiXhosa.

Objectives: This study explores the nature of spelling among Grade 3 isiXhosa home-language learners and provides a linguistic analysis of the types of errors produced by these learners.

Method: Data were collected from 51 isiXhosa home-language learners using a carefully designed isiXhosa spelling task, which included both real and pseudowords.

Results: The findings showed that grapheme complexity was a significant predictor of spelling error production in isiXhosa. Furthermore, the main error type for both real words and pseudowords was errors of omission, specifically $\langle n\rangle$ in nasal blends and $\langle h\rangle$ in aspirated digraphs.

Conclusion: While the isiXhosa orthography is transparent, and thus relatively predictable in decoding, its agglutinative, conjunctive character coupled with the existence of a number of complex graphemes presents a greater challenge for spelling. This supports the need for targeted instruction of complex graphemes in isiXhosa pedagogical practice to improve encoding skills.

Keywords: spelling; spelling errors; literacy; isiXhosa; Southern Bantu languages.

\section{Introduction}

It is well documented that South Africa is in the midst of a literacy crisis, with a growing body of literature that highlights the country's literacy underachievement (De Sousa \& Broom 2011; De Vos, Van der Merwe \& Van der Mescht 2014; Pretorius \& Mokhwesana 2009; Spaull 2013; Spaull, Pretorius \& Mohohlwane 2020). In particular, the Progress in International Reading Literacy Studies (PIRLS) (Howie et al. 2008, 2012, 2017) have shed light on the literacy underperformance of South African children in comparison with international standards. For example, in the latest PIRLS (Howie et al. 2017), South Africa was placed last out of 50 countries, which translates as South African learners lagging six years behind those learners from the top-performing countries. In addition, $78 \%$ of these learners are unable to read for meaning (Howie et al. 2017). A greater cause for concern is that learners learning to read in a Southern Bantu language attained the lowest scores, with $88 \%$ of isiXhosa learners unable to read for meaning compared with $57 \%$ in the English language group (Howie et al. 2017).

There are many contributing factors to the literacy crisis (De Vos, Van der Merwe \& Van der Mescht 2015), which include, but are not limited to, social factors such as low adult literacy levels, family background and poverty (Pretorius \& Mokhwesana 2009). Additionally, there are a number of contributing schooling factors such as weak institutional functionality, resource shortages, overcrowded classrooms, weak teacher content knowledge and pedagogical skill, and wasted learning time (Pretorius \& Mokhwesana 2009; Van der Berg et al. 2016). In addition, there remains a lack of understanding of exactly how literacy develops in the Southern Bantu languages (De Vos et al. 2015). An understanding of the linguistic literacy skills that contribute to reading success in these languages can assist in developing pedagogically sound curricula and teaching practices. The current article reports on an investigation into a largely neglected variable in the understanding of reading development, which is that of spelling (Fleisch, Pather \& Motilal 2017; Schaefer \& Kotzé 2019; Treiman 2017). Specifically, the main purpose is to explore the nature of spelling in isiXhosa by identifying the patterns of spelling errors made by isiXhosa home-language Grade 3 learners.

Note: This article was republished with the spelling error in 'Southern Bantu langauges' corrected to 'Southern Bantu languages' in five instances. The publisher apologises for any inconvenience caused. 


\section{Literature review}

In comparison with research on reading, there has been less research done on spelling. In particular, research looking specifically at spelling error analysis in South Africa is extremely sparse. Conceptualising spelling requires an understanding that spelling is not a single skill but rather involves the integration of several skills. If one were to simplify it, spelling is understood as a process of encoding, in which spoken words are converted into written symbols (Mpiti 2012). Studies on spelling have centred around three central topics (Fleisch et al. 2017). The first deals with the developmental stages of spelling, the second the relationship between spelling and reading and the last, to a lesser extent, the linguistic categories and analysis of spelling errors (Fleisch et al. 2017). These topics have been explored predominately in English, with few studies focusing on African languages (Alcock \& Ngorosho 2003, 2007; De Sousa, Greenop \& Fry 2011; Diemer, van der Merwe \& de Vos 2015). In our literature review, we address the skills involved in spelling, generally, and spelling in alphabetic orthographies, and describe research relating to spelling error analysis.

\section{Skills involved in spelling}

Spelling involves the integration of several skills including phonological, morphological and orthographic awareness (Ehri \& Wilce 1982; Pijper 2003; Swayer \& Joye 2006; Wagner \& Torgesen 1987).

Phonological awareness (PA), which refers to the awareness and ability to manipulate sounds of one's language (Anthony et al. 2003), has been identified as an important contributor to spelling (Bruck \& Treiman 1990; Treiman 1993; Vellutino et al. 2004). Specifically, PA enables children to learn phoneme-grapheme correspondences, which is useful for creating accurate spellings (Griffith 1991). For example, Weinrich and Fay (2007) found that phonemic awareness skills were significant in predicting spelling ability in Englishspeaking children. In the South African context, De Sousa et al.'s (2011) study, which investigated spelling performance by 30 emergent bilingual isiZulu-English and 30 monolingual English children in Grade 2, argued that PA is well represented in spelling. The findings of their study showed that first-language (L1) PA is related to spelling across languages in emergent bilinguals. They assert that an awareness of phonemes and their ability to be segmented and manipulated enhances learners' decoding skills, which leads to spelling success (De Sousa et al. 2011). Similarly, Diemer's (2015) study noted that spelling is directly related to phonological representations but is also influenced by grammatical knowledge. She found that spelling in isiXhosa was significantly influenced by PA.

Morphological awareness (MA) has also been shown to play a role in spelling (see Apel \& Masterson 2001; Mann \& Singson 2003; Nunes \& Byrant 2009). Nunes, Bryant and Bindman (1997)'s study showed that in English, scores on a MA task (namely word and sentence analogy) predicted 6-8-year-old children's successful spelling of the regular past tense verbs as -ed in both words and pseudowords, even after controlling for PA. Furthermore, Deacon, Kirby and Casselman-Bell's (2009) study showed that MA is a robust variable in predicting spelling outcomes. Results of their study showed that MA measured in Grade 2 determined $8 \%$ of the variance in spelling measured two years later, even after controlling for verbal and nonverbal intelligence, PA, short-term memory and rapid automated naming. These results demonstrate that MA has a significant role in children's spelling development.

In addition, orthographic knowledge is important for spelling in that learners are expected to engage with the orthographic features of a language such as the letter names and sounds or alphabetic, within-word patterns and syllable structure (Fleisch et al. 2017). Therefore, Templeton and Morris (2000) reason that if learners are not able to memorise the complete and accurate orthographic representation of a word, then their ability to spell a word will reflect the orthographic knowledge they were able to utilise in processing the word for spelling. Zaric, Hasselhorn \& Nagler's (2020) study on German children provides further support for the role of orthographic awareness in spelling, with their results showing that word-specific, as well as general orthographic knowledge contributes to spelling performance, over and above intelligence and PA. Similarly, Mpiti (2012) argues that spelling involves visual memory and the knowledge of orthographic rules and conventions (Kress as cited in Pijper 2003; Richards 2001:14; Wagner \& Torgesen 1987).

Thus, with respect to the skills required for spelling, children need to simultaneously integrate not only phonological, but also morphological, orthographic, lexical and grammatical knowledge in order to become accomplished spellers (Alcock \& Ngorosho 2003). However, little is known about spelling in the Southern Bantu languages and thus the relationship of the above listed metalinguistic skills to spelling in isiXhosa should be interpreted within this constraint.

\section{Spelling in an alphabetic language}

The knowledge of orthography, defined as the understanding of the conventions used in the writing system of one's language (Treiman \& Cassar 1996), has been shown to facilitate children's spelling development. Thus, in an alphabetic writing system, spelling involves the process of mapping grapheme to phoneme (Park 2011). Given that isiXhosa is an alphabetic language, this section reviews spelling in alphabetic languages.

Caravoles' (2004) cross-linguistic study of alphabetic languages highlighted both the similarities and differences between alphabetic orthographies and how these impact spelling development. In particular, the study reviewed English, French and Czech studies to uncover what spelling acquisition characteristics are universal and which are language specific (Caravoles 2004). Caravoles acknowledges that studies focusing on spelling development in languages other than English are significantly rare and, thus, her study 
provides only preliminary insights into spelling development across languages.

She notes that alphabetic orthographies share one key and possibly universal quality (Caravoles 2004): they are all based on the alphabetic principle, which is the understanding that graphemes represent particular phonemes in spoken language (Caravoles 2004). However, she explains that the extent to which languages adhere to the alphabetic principle will determine the degree to which learners can exploit the principle when spelling (Caravoles 2004:4).

Alphabetic languages exist on a continuum between transparent, in which there is a consistent one-to-one mapping of phoneme to grapheme, and opaque, where there is an inconsistent mapping of phoneme to grapheme. Depending on the type of orthography, learners are required to use different types of orthographic and linguistic knowledges when spelling (Caravoles 2004:4). Only few cross-linguistic studies have examined spelling development in relation to the consistency of the orthography. Concerning the languages of focus in Caravoles' (2004) study, English is considered opaque and Czech is considered transparent. Similarly, isiXhosa is also considered a transparent language. Caravoles' review revealed that learners learning to spell in more consistent orthographies tended to perform better than their English counterparts. This was rationalised under the understanding that orthographic consistency promotes faster spelling development and thus learners are able to learn the basic phonological spelling skills and conventional spelling skills with more ease (Caravoles 2004). However, Bigozzi et al. (2016:2) argue that spelling is made more challenging in transparent orthographies, in which the regularity of the orthographic system is higher in grapheme-phoneme relations (forward regularity, e.g. decoding) than it is in phoneme-grapheme relations (backward regularity, e.g. encoding). Caravoles' study showed that there are clearly differences in spelling development across alphabetic orthographies and recommends that further cross-linguistic longitudinal studies be conducted on languages other than English to confirm or deny the preliminary findings. This provides further motivation for studies of this nature.

Other noteworthy variables mentioned in Caravoles' (2004) study that seem to play a role in spelling development in alphabetic orthographies include the morphological information encoded in the languages and its impact on the phoneme-grapheme consistency (Caravoles 2004), the presence of borrowed words that have retained their spelling from their host language, archaic spellings that reflect historical word pronunciations, pedagogical practice, home literacy, phonotactic constraints and syllable structure (Caravoles 2004).

\section{Spelling error analysis}

There is a growing body of research dedicated to the exploration of patterns in spelling errors in attempts to facilitate our understanding of reading underachievement (Fleisch et al. 2017).

Bahr et al. (2012:6) state that the qualitative evaluation of linguistic patterns of spelling errors is important for two reasons. Firstly, the study of the patterns of spelling errors can enhance our understanding of how learners with language impairments organise their phonological, orthographic and morphological knowledge (Bahr et al. 2012). Secondly, broader knowledge about spelling errors can lead to the creation of individualised instruction and intervention programmes for learners (Bahr et al. 2012). It is for the above-mentioned reasons that spelling errors are the focus of the current study.

Cook's (1999) classification of errors (namely omission, substitution, insertion and transposition) has been used by researchers to qualitatively categorise spelling errors, especially in studies seeking to understand how to better teach English as a second language (Alhaisoni, Al-Zuoud \& Gaudel 2015; Golshan \& Reigani 2015; Khider \& Othman 2018). Further, these categories have also been used in research on word recognition in English and isiXhosa (Probert \& De Vos 2016).

Alcock and Ngorosho's (2003) study looked at spelling development in Kiswahili with a focus on the patterns of errors made in Kiswahili writing. Kiswahili is a Southern Bantu language which is similar in structure to isiXhosa. While they did not exclusively use Cook's (1999) classification of errors, the error types identified lend themselves quite closely to those used by Cook but with more precise margins. The results of the 50 real-word spelling task revealed that the most common errors identified, were those containing digraphs followed by the confusion of the letters $\langle l\rangle$ and $\langle r\rangle$ and the addition and omission of $\langle h\rangle,\langle y\rangle$ and $\langle w\rangle$. Another prominent error type identified was the omission of a nasal consonant in a 'consonant cluster' (Alcock \& Ngorosho 2003). The latter result was reaffirmed in a later study by Alcock \& Ngorosho (2007), in which they found that consonant clusters consisting of a nasal consonant in the initial position of a word followed by an additional consonant were more difficult to spell than words that contained either type of consonant in isolation. This result was reasoned to be as a consequence of the lack of salience of consonant clusters in Kiswahili (Alcock \& Ngorosho 2007). They concluded that spelling is different to reading in transparent languages in that phonological decoding is a necessary but insufficient skill needed for spelling success (Alcock \& Ngorosho 2003), suggesting that there may be other skills more significant for spelling success in African languages (Alcock \& Ngorosho 2003). More research is needed on the skills underpinning spelling in African languages.

Research looking specifically at spelling error analysis in South Africa is extremely sparse. Fleisch et al.'s (2017) study, which investigated spelling errors made by English secondlanguage learners, is one of the first to provide an in-depth understanding of the patterns and prevalence of spelling 
errors in South Africa. It focused on monosyllabic threeletter word spelling errors and provided important insights into the understanding of second-language reading underachievement (Fleisch et al. 2017). The data for their study were drawn from previously conducted learner literacy tests as part of a randomised control trial. Their findings revealed that over two-thirds of the 2500 learners misspelled simple monosyllabic three-letter English words which are assumed by the national curriculum to have been taught in the second term of Grade 2, confirming the large body of research about the reading and writing underachievement of learners (Fleisch et al. 2017). The most prevalent error type identified was associated with the incorrect identification of the middle vowel sound, an indication of weakness in phoneme awareness (Fleisch et al. 2017). The findings also showed low levels of encoding in the spelling test which imply that the learners were failing at the initial 'learning to read' foundational skills (Fleisch et al. 2017). Fleisch et al. provided an in-depth analysis of error categories that were present in the learner data, which they later refined to the linguistic categories: alphabetic, L1 interference and vowel error. According to Fleisch et al. (2017), the growing exploration into the identification of error patterns in spelling could prove useful in facilitating our understanding of reading underachievement and how it can be incorporated into pedagogy. This is because the study of learners' spelling errors provides an opportunity to understand and facilitate the learners' spelling difficulties (Al-zuoud \& Kabilan 2013).

While Fleisch et al.'s (2017) study was instrumental in introducing a body of knowledge dedicated to understanding spelling errors in the South African context, a gap remains in exploring error patterns in Southern Bantu languages, specifically L1 spelling in isiXhosa. In this currently underexplored domain, this research on spelling is important as it adds to the growing understanding of literacy in Southern Bantu languages.

\section{Language structure of isiXhosa}

IsiXhosa is an agglutinative language (Probert \& De Vos 2016). Consequently, a single orthographic word in isiXhosa can represent a whole sentence (Spaull, Pretorius \& Moholwane 2020). For example, the orthographic word Ndibabuzile in isiXhosa ('I asked them') has the stem -buz'ask' with separate morphemes ndi- ba- and -ile attached. Words in isiXhosa therefore tend to be longer than their English equivalents due to the extensive use of affixation on nouns and verbs in isiXhosa (Probert \& De Vos 2016). For example, the verb in isiXhosa allows for nine positions into which a grammatical morpheme may slot (Gxilishe et al. 2009). These include subject and object, tense, negation, causative, applicative and so forth (Gxilishe et al. 2009). This is illustrated in (1) below:

(1) Abantu abasebenzi

Aba-ntu a-ba-sebenz-1

NC2-people neg-SM-WORK-neg

'The people are not working'
Moreover, isiXhosa has a transparent and conjunctive orthography. In conjunctive orthographies, linguistic words and orthographic words coincide. This is seen in the example Ndibabuzile given above. However, in disjunctive orthographies, such as Sesotho, linguistic words and orthographic words do not coincide. Furthermore, because of its conjunctive orthography there are relatively few free morphemes, and single syllable words are less common. There are also many complex graphemes in the language, including diagraphs $(\langle d l\rangle,\langle p h\rangle,\langle t l\rangle)$, trigraphs $(\langle n g w\rangle,\langle k g w\rangle)$ and four-letter consonant sequences $(\langle n t h\rangle)$ (Spaull et al. 2020). Alternatively, it can be argued that the complex graphemes allow for more combinations to learn, which results in longer learning times. Orthographic knowledge in isiXhosa can thus be rather dense and can make spelling a challenging task for learners. Therefore, while the isiXhosa orthography is transparent and relatively predictable in decoding, its agglutinative, conjunctive character coupled with the existence of a number of complex graphemes presents a greater challenge for spelling (the encoding of phoneme to grapheme). Research is thus needed on spelling, and on the types of errors learners encounter when spelling in isiXhosa.

With this in mind, the following two research questions are addressed in this study:

- What is the spelling ability of Grade 3 isiXhosa homelanguage learners?

- What are the patterns of spelling errors made by Grade 3 isiXhosa home-language learners?

\section{Methodology Participants and research setting}

This study is a small-scale, exploratory study, which used a cross-sectional design. The study was conducted at a Quintile 3 primary school on the outskirts of a township in the Eastern Cape. IsiXhosa is used as the language of learning and teaching (LoLT) at the school until the end of Grade 3, after which a transition is made to English as the LoLT. All participants in this study were Grade 3 isiXhosa homelanguage learners. However, participants' exposure to and use of English in daily activities varied. Participants comprised 51 Grade 3 home-language isiXhosa learners, which included 21 boys and 30 girls. The average age of the participants was 8 years old.

All learners participated on a voluntary basis after returning informed consent forms signed by their parents or guardians, as well as providing their own verbal assent. All learners' identities were kept confidential.

\section{Measures}

A standardised spelling task for the Southern Bantu languages has yet to be developed. Therefore, taking into consideration the literature, and keeping to the phonological and orthographic structure of isiXhosa, an isiXhosa spelling task was developed. This spelling task included two subtasks: a real word and pseudoword task. 


\section{Spelling task}

The spelling task was group-administered by trained research assistants who are isiXhosa home-language speakers. Words were read aloud one by one and then repeated once more. Learners were informed that they would first be spelling the real words followed by the pseudowords. The research assistant informed them when the transition was made. The spelling task consisted of 24 items, which included 12 real words and 12 pseudowords.

The design of the spelling task took into account three considerations, namely frequency, grapheme complexity and word length in syllables (word length). For the real word spelling task, words were sourced from a list of the top 300 high frequency words in isiXhosa, which was drawn from a corpus of 170000 tokens of isiXhosa words (Rees \& Randera 2019). Grapheme complexity was controlled for, as it has been noted that spelling in Southern Bantu languages seems to be more difficult due to the variety of complex graphemes and the agglutinative nature of the language, which makes words longer and denser (Diemer 2015). With respect to grapheme complexity, a range of words including those containing no complex graphemes to those with multiple complex graphemes were included. The third consideration was word length. The length consideration ensured that words ranged from disyllabic to quadrisyllabic. Lastly, to ensure that the task was fair and appropriate, all real words chosen had lexical meaning. The pseudoword spelling task was designed to be symmetrical as far as possible to the real word spelling task. As such, grapheme complexity and word length were controlled for.

Pseudowords were used as participants cannot rely on prior knowledge to spell the words but have to access their own graphemic knowledge of the language. This allows for a true representation of the learners' encoding abilities. A list of real words and pseudowords used in the spelling task are included as Table 1-A1 and Table 2-A1 of Appendix 1.

\section{Data coding and analysis}

Once the task was administered, the spelling subtask was coded using a binary set of codes, that is, correct and incorrect.

A secondary analysis was performed on the results documenting the errors found in the spelling tasks. The errors were coded according to Cook's (1999) classification of errors (namely omission, substitution, insertion and transposition), with additional error categories included, based on the error types identified in the data. Thus, the error categories used for this study were: blank, illegible, alphabetic (errors in which there were more than three graphemes added or excluded, or which had no phonetic or orthographic relation to the target word), omission (leaving out graphemes), substitution (replacing graphemes with incorrect ones), insertion (adding of incorrect graphemes), transposition (swapping graphemes around) and graphemes written backwards.

\section{Ethical consideration}

Ethical clearance was obtained from the Rhodes University Ethical Standards Committee and the Eastern Cape Department of Basic Education (Nr 2019-0461-452).

\section{Results}

The results of the study are organised as follows: (1) Grade 3 spelling scores and (2) patterns of spelling errors. Cronbach's alpha values were used to assess the reliability of the spelling task. The Shapiro-Wilk normality test revealed that data were not normally distributed $(p<0.001)$ for both real word and pseudoword subcomponents of the spelling task.

Research question 1: What is the spelling ability of Grade 3 isiXhosa home-language learners?

Although the main focus of this study was not on the proportion of correct and incorrect spelling, but rather on the specific patterns of spelling errors, it is nonetheless important to first establish an understanding of the learners' spelling ability. The average mark for the spelling task (both real words and pseudowords) was 15.8 (65.8\%). The descriptive statistics for the spelling results are depicted in Table 1.

From Table 1, it is evident that the learners performed better on the real word spelling task $(M=9.37, \mathrm{SD}=3.96)$, than on the pseudoword task $(M=6.45, \mathrm{SD}=3.35)$. A paired $t$-test revealed that this difference in performance was statistically significant $(t=-10.3, p<0.001 ;$ Cohen's d $=-1.44)$.

Research question 2: What are the patterns of spelling errors made by Grade 3 isiXhosa home-language learners?

The results of the real word and pseudoword spelling tasks are presented below. In particular, this section outlines the types of linguistic errors the learners made on each task and the pertinent patterns identified in the types of errors produced.

\section{Real word spelling results}

The words that were most incorrectly spelled were phandle (33.3\%), ngaphakathi (29.45\%) and umakhulu (29.45\%). The words with the most errors recorded were ngaphakathi (24 errors), phandle (21 errors) and namhlanje (21 errors).

The words that were least incorrectly spelled were oku $(10 \%)$, amanzi $(14 \%)$ and amabali $(16 \%)$. These words also contained the lowest number of errors with five, seven and eight errors made per word. As noted in the methods

TABLE 1: Descriptive statistics $(N=51)$.

\begin{tabular}{lcccccc}
\hline Test section & Mean & SD & Minimum & Maximum & $\begin{array}{c}\text { Zero scores } \\
(\mathbf{\%})\end{array}$ & Reliability $\boldsymbol{\alpha}$ \\
\hline Spelling (/24) & 15.8 & 7.05 & 0 & 24 & 15.7 & 0.947 \\
$\begin{array}{l}\text { Real word } \\
\text { spelling (/12) }\end{array}$ & 9.37 & 3.96 & 0 & 12 & 7.8 & 0.95 \\
$\begin{array}{l}\text { Pseudoword } \\
\text { spelling (/12) }\end{array}$ & 6.45 & 3.35 & 0 & 12 & 7.8 & 0.839 \\
\hline
\end{tabular}


TABLE 2: Linear regression: Real word errors predicted.

\begin{tabular}{lccccc}
\hline Number of errors per word & Estimate & Standard error & $\boldsymbol{\beta}$ & $\boldsymbol{t}$-statistic & $\boldsymbol{p}$ \\
\hline Intercept & 4.295 & 3.97 & - & 1.083 & 0.307 \\
Length & 0.723 & 1.24 & 0.10 & 0.584 & 0.574 \\
Complexity & 5.213 & 1.07 & 0.84 & 4.858 & $<0.001$ \\
\hline
\end{tabular}

section, the words ranged in length and grapheme complexity as a means to determine which of these factors influenced the learners' spelling to a greater extent. Therefore, in order to precisely identify the degree to which word length or grapheme complexity influenced the spelling results, a linear regression was conducted with the number of errors made per word as the predicted variable and word length and grapheme complexity as predictor variables. This is illustrated in Table 2.

The model revealed that word length and grapheme complexity account for $73 \%$ of the number of errors made per word $\left(R^{2}=0.734, p<0.05\right)$. Only grapheme complexity was a significant predictor $(\beta=0.84, p<0.001)$. It is therefore evident that grapheme complexity is a primary factor influencing the production of errors in the real word spelling task.

In terms of the types of errors made by the learners, the most prevalent error types identified were errors of omission (34.7\%) and alphabetic errors (25\%). Furthermore, the incorrect representation of complex graphemes accounted for $49 \%$ of the overall errors made by learners. This supports the view that the difficulty for spelling in isiXhosa lies in the presence of complex graphemes. In particular, learners struggled with the representation of digraphs, aspirated digraphs and nasal blends, with the words with the highest error rates being ngaphakathi (24 errors) and phandle (21 errors), each of which contains these complex graphemes.

In particular, the most common omitted letters were the omission of $\langle h\rangle$ in aspirated digraphs such as $\langle p h\rangle,\langle k h\rangle$ and $\langle t h\rangle$ found in the words phandle, umakhulu and ngaphakathi, and the letter $\langle n\rangle$ in nasal blends, consonant blends and digraphs that begin with the letter $\langle n\rangle$, such as $\langle n d l\rangle$ in phandle, $\langle n j\rangle$ in namhlanje, $\langle n d\rangle$ in amaqanda and $\langle n g\rangle$ in ngaphakathi. There were no significant trends in the substitutions of letters for the real word spelling task.

\section{Pseudoword spelling results}

The learners performed significantly worse on the pseudoword spelling task than the real word spelling task $(t=-10.3, p<0.001)$, but this is to be expected as the learners would never have encountered these words before and the real words were chosen specifically from a list of high frequency isiXhosa words.

The words that were spelled most incorrectly were ingxembo $(86.3 \%)$, tshafiba $(78.4 \%)$ and khuqahleyo $(60 \%)$. The words with the most errors recorded were ingxembo (60 errors), khuqahleyo (53 errors) and tshafiba (52 errors). The words that were least incorrectly spelled were tuza (21\%), lwesha (25\%) and ngela (27\%). These words also contained the lowest
TABLE 3: Linear regression: Pseudoword error predicted.

\begin{tabular}{lccccc}
\hline Number of errors per word & Estimate & Standard error & $\boldsymbol{\beta}$ & $\boldsymbol{t}$-statistic & $\boldsymbol{p}$ \\
\hline Intercept & -8.02 & 14.99 & - & -0.535 & 0.606 \\
Length & 8.02 & 4.39 & 0.396 & 1.826 & 0.101 \\
Complexity & 12.74 & 4.22 & 0.655 & 3.019 & 0.015 \\
\hline
\end{tabular}

number of errors with 12,15 and 15 errors made per word. As noted in the real word error analysis, the words ranged in word length and grapheme complexity as a means to determine which of these factors influenced the learners' spelling to a greater extent.

As was done with the real words, a linear regression was conducted to observe whether word length or grapheme complexity was a stronger predictor of error rates in the pseudowords. The results of the linear regression are reported in Table 3.

The model reaffirmed the results of the real word analysis. The model showed that word length and grapheme complexity combined account for $58 \%$ of the variance in the number of errors made per word $\left(R^{2}=0.576, p<0.05\right)$ with grapheme complexity being the only significant predictor ( $\beta=0.655, p<0.05)$ contributing $65 \%$ of the variance in error production. These results, therefore, confirm that the presence of complex graphemes in isiXhosa presents a challenge to learners when spelling.

In terms of the types of errors made by the learners, the most prevalent error types identified were omission errors (35\%) and substitution errors (34\%). Furthermore, the incorrect representation of complex graphemes accounted for 55\% of the overall errors made by learners, with the learners struggling mainly with the representation of the nasal blends $\langle n g x\rangle$ and $\langle m b\rangle$ the aspirated digraph $\langle k h\rangle$, the click $\langle q\rangle$ and the digraph $\langle h l\rangle$, all of which appear in the words with the highest error rates.

Of the $35 \%$ of omission errors made, the most common omitted letters were $\langle g\rangle$ in the word ingxembo, $\langle h\rangle$ in nokhubela and $\langle n\rangle$ in inkweseva. Of the $34 \%$ of substitution errors made, the most common substitutions were the substitution of $\langle d l\rangle$ in ndlashaza for other digraphs such as $\langle h l\rangle$ or $\langle t l\rangle$, the substitution of $\langle m b\rangle$ in ingxembo for $\langle g\rangle$, $\langle l\rangle$, or $\langle n g\rangle$, the substitution of $\langle v\rangle$ in inkweseva for $\langle m b\rangle,\langle z\rangle$ or $\langle b\rangle$, and the substitution of $\langle h l\rangle$ in khuqahleyo for a variety of different letters, for example $\langle s h\rangle$ and $\langle k\rangle$. Of the $11 \%$ of insertion errors, the most common inserted letter was $\langle n\rangle$ in the word initial position of tshafiba.

\section{Discussion}

The findings of this study help to provide insight into the types of difficulties learners may face when spelling in isiXhosa. The main purpose was to explore the nature of spelling in isiXhosa by identifying the patterns of spelling errors made by isiXhosa home-language Grade 3 learners.

The results show that the isiXhosa home-language learners performed significantly better on the real word spelling task 
than on the pseudoword spelling task. This is to be expected, as the real words were all high frequency words in isiXhosa. In terms of the essential skills necessary for spelling as noted by Mpiti (2012), the results of the real words spelling task indicate that many of the learners have mastered many of the phonological representations of the real words and have been able to recall their spelling from their visual memory. However, since the learners cannot rely on their visual memory for pseudowords, they are required to draw largely from their knowledge of phonological representations of the sounds and thus the poor results of the pseudoword spelling task $(M=6.45)$ could be due to poor PA skills. This is because, as shown in Diemer (2015), PA and spelling are closely correlated, and together with phoneme identification and phoneme segmenting account for $50 \%$ of the variance in spelling in isiXhosa Grade 3 learners.

The error analysis revealed that for both the pseudoword and real word spelling task grapheme complexity is a significant predictor of spelling error production in isiXhosa. These results provide empirical evidence supporting Diemer (2015) who suggested that orthographic knowledge, in reference to complex graphemes in isiXhosa, can be rather dense and can make spelling a challenging task for learners. Furthermore, the results support both Caravoles (2004) and Bigozzi et al. (2016) who noted that orthographic complexity, more specifically inconsistencies in phoneme-grapheme and grapheme-phoneme correspondences, can make spelling challenging for learners. The challenges experienced by learners with complex graphemes in spelling may also be indicative of poor PA, and lack of phonics instruction, which makes build-up of orthographic awareness slower.

Notably, the most common errors in both the pseudoword and real word spelling tasks were errors of omission. Specifically, for the real word task, it was the omission of $\langle n\rangle$ in nasal blends, $\langle n d l\rangle,\langle m h l\rangle$ and $\langle n g x\rangle$, and $\langle h\rangle$ in aspirated digraphs $\langle k h\rangle,\langle p h\rangle$ and $\langle t h\rangle$. Similarly, for the pseudoword task learners struggled mainly with the representation of the nasal blends $\langle n g x\rangle$ and $\langle m b\rangle$, the aspirated digraph $\langle k h\rangle$, the click $\langle q\rangle$ and the digraph $\langle h l\rangle$, with the most common omitted letters being $\langle g\rangle,\langle h\rangle$ and $\langle n\rangle$. These results are similar to those found by Alcock and Ngorosho (2003) for whom the most common errors identified were the addition and omission of $\langle h\rangle,\langle y\rangle$ and $\langle w\rangle$ and the omission of nasal consonants in a 'consonant cluster' (Alcock \& Ngorosho 2003, 2007). This result was reasoned to be a consequence of the lack of salience of consonant clusters in Kiswahili (Alcock \& Ngorosho 2007). However, in isiXhosa there are many complex graphemes in the language and, in particular, the aspirated digraphs and nasal blends are high frequency phonemes in the language.

One possible explanation for the prevalence of errors of omission could be as a result of the inconsistency of the grapheme to phoneme correspondence with complex graphemes in isiXhosa. IsiXhosa has a transparent orthography. Thus, typically there is a one-to-one mapping of phonemes to graphemes in the language. Furthermore, the language typically follows an open consonant-vowel syllable structure. However, with complex graphemes, often more than one grapheme corresponds to a single phoneme, for example $\langle p h\rangle,\langle m h l\rangle,\langle n g x\rangle$ and $\langle n c w\rangle$. Thus, it may be the case that the learners are omitting the letters of the graphemes so as to adhere to the consonant-vowel structure of the language and one-to-one mapping of phoneme to grapheme. It could also be that the learners have not yet acquired the representations of said graphemes or they have not received explicit instruction regarding the representation of complex graphemes. In either event, complex graphemes form an important part of isiXhosa orthography and the lack of knowledge of their representation influences a learner's orthographic awareness. Templeton and Morris (2000) state that if learners are not able to memorise the 'full conventional orthographic representation' of a word, then their ability to spell a word will illustrate the orthographic knowledge that they have used to process said word. Thus, the prominence of omission in relation to complex graphemes suggests that the learners do not have sufficient orthographic knowledge of complex graphemes.

Another prominent error identified was alphabetic errors, which include all errors in which there were more than three graphemes added or excluded, or there was no phonetic or orthographic relation to the target word. This error category was used by Fleisch et al. (2017) and referred to similar characteristics as mentioned in this study. According to Fleisch et al. the prevalence of this error type indicates that learners have not yet acquired the basic understanding of the relationship between phoneme and graphemes, which is a key stage in learning to read. It is interesting that the learners made more alphabetic errors in the real word task $(25.3 \%)$ than in the pseudoword task $(14 \%)$ as one could assume that they would rely on their prior knowledge to spell the words and thus make individual graphemic errors in their attempts to spell the words, with some resemblance of the target word intact. This was not the case, as the alphabetic errors had no phonetic or orthographic resemblance to the target word. This further suggests that these learners have poor phonological or orthographic awareness.

\section{Conclusion}

The main research objective of this study was to investigate the nature of spelling in isiXhosa, and identify the patterns of errors in isiXhosa spelling. In terms of the learners' spelling performance, the findings showed that learners performed significantly better on the real word spelling task $(M=9.37, \mathrm{SD}=3.96)$ than on the pseudoword task $(M=6.45$, $\mathrm{SD}=3.35$ ). With respect to the types of errors learners made, the findings revealed that the main type of error in the real word task and pseduoword task were errors of omission. In particular, the learners appeared to struggle mainly with nasal blends and nasal digraphs $(\langle n d l\rangle,\langle n g x\rangle,\langle n k w\rangle,\langle n d\rangle$ and $\langle n g\rangle)$, and aspirated digraphs $(\langle k h\rangle,\langle p h\rangle$ and $\langle t h\rangle)$, omitting the $\langle n\rangle$ or $\langle h\rangle$. Nasals tend be omitted when they were the initial consonant in a grapheme cluster. Further, grapheme 
complexity was found to be a significant predictor of spelling difficulty in isiXhosa, which supports the patterns of errors identified in the error analysis. Therefore, while the isiXhosa orthography is transparent and relatively predictable in decoding, its agglutinative, conjunctive character coupled with the existence of a number of complex graphemes presents a greater challenge for spelling.

The pedagogical implications of these results are as follows: since grapheme complexity is a significant predictor of spelling difficulty in isiXhosa, this suggests that greater attention should be paid to teaching learners the representation of complex graphemes in isiXhosa as a means to enhance their spelling ability, orthographic awareness and PA. Fleisch et al. (2017) state that teaching learners about spelling conventions will, as a direct consequence, improve their spelling and reading knowledge. In addition, Arndt and Foorman (2010) highlight the pedagogical implications of educators focusing on the improvement of spelling ability, targeting the learners' weaknesses particularly, as a way to create better readers. Therefore, further research into spelling in isiXhosa is vital as it may enable meaningful contributions to be made to current pedagogical practices.

Since there is no research on spelling patterns in isiXhosa, it was difficult to conduct a reflection or comparison to related research. Thus, there is an urgent need for further research to confirm the above findings and to investigate the possible causal elements contributing to the gaps in learners' spelling ability in isiXhosa. We believe that this study provides a glimpse into unexplored territory that could provide valuable information for future literacy research. Furthermore, insight provided from this study may also assist in motivation for the design of more individualised instruction and intervention regarding spelling in isiXhosa, based on research in isiXhosa, and facilitate our understanding of literacy underachievement in South Africa as a whole.

\section{Acknowledgements}

Thank you to Maxine Schaefer, Tracy Kitchen and Gwyn Ortner who proofread earlier versions of this article.

\section{Competing interests}

The authors have declared that no competing interests exist.

\section{Authors' contributions}

All authors contributed equally to this work.

\section{Funding information}

This research received funding support from the Rhodes University Research Committee Grant Fund.

\section{Data availability statement}

The data that support the findings of this study are available from the corresponding author, T.N.P., upon reasonable request.

\section{Disclaimer}

The views and opinions expressed in this article are those of the authors and do not necessarily reflect the official policy or position of any affiliated agency of authors.

\section{References}

Alcock, K.J. \& Ngorosho, D., 2003, 'Learning to spell a regularly spelled language is not a trivial task - Patterns of errors in Kiswahili', Reading and Writing 16(7), 635-666. https://doi.org/10.1023/A:1025824314378

Alcock, K. \& Ngorosho, D., 2007, 'Learning to spell and learning phonology: The spelling of consonant clusters in Kiswahili', Reading and Writing 20(7), 643-670. https://doi.org/10.1007/s11145-006-9043-9

Alhaisoni, E.M., Al-zuoud K.M. \& Gaudel, D.R., 2015, 'Analysis of spelling errors of Saudi beginner learners of English enrolled in an Intensive English Language Program', English Language Teaching 8(3), 185-192. https://doi.org/10.5539/elt. v8n3p185

Al-zuoud, K.M. \& Kabilan, M., 2013, 'Investigating Jordanian EFL students' spelling errors at tertiary level', International Journal of Linguistics 5(3), 164-176. https:// doi.org/10.5296/ijl.v5i3.3932

Anthony, J.L., Lonigan, C.J., Driscoll, K., Phillips, B.M \& Burgess, S.R., 2003, 'Phonological sensitivity: A quasi-parallel progression of word structure units and cognitive operations', Reading Research Quarterly 38(4), 470-487. https://doi. org/10.1598/RRQ.38.4.3

Apel, K. \& Masterson, J.J., 2001, 'Theory-guided spelling assessment and intervention: A case study', Language, Speech, and Hearing Services in the Schools 32(3), 182-195.

Arndt, E.J. \& Foorman, B.R., 2010, 'Second graders as spellers: What types of errors are they making?', Assessment for Effective Intervention 36(1), 57-67. https://doi. org $/ 10.1177 \% 2$ F1534508410380135

Bahr, R.H., Sillian, E.R., Berninger, V.W. \& Dow, M., 2012, 'Linguistic pattern analysis of misspellings of typically developing writers in grades 1-9', Journal of Speech, Language, and Hearing Research: JSLHR 55(6), 1587-1599. https://doi. org/10.1044/1092-4388(2012/10-0335)

Bigozzi, L., Tarchi, C., Caudek, C. \& Pinto, G., 2016, 'Predicting reading and spelling disorders: A 4-year prospective cohort study', Frontiers in Psychology 7. https:// doi.org/10.3389/fpsyg.2016.00337

Bruck, M. \& Treiman, R., 1990, 'Phonological awareness and spelling in normal children and dyslexics: The case of initial consonant clusters', Journal of Experimental Child Psychology 50(1), 156-178. https://doi.org/10.1016/00220965(90)90037-9

Caravoles, M., 2004, 'Spelling development in alphabetic writing systems', European Psychologist 9(1), 3-14. https://doi.org/10.1027/1016-9040.9.1.3

Cook, V.J., 1999, 'Teaching spelling', viewed 03 May 2008, from http://homepage. ntlworld.com/vivian.c/Writings/Papers/TeachingSpelling..htm.

Deacon, S.H., Kirby, J.R. \& Casselman-Bell, M., 2009, 'How robust is the contribution of morphological awareness to general spelling outcomes?', Reading Psychology 30(4), 301-318. https://doi.org/10.1080/02702710802412057

De Sousa, D.S. \& Broom, Y., 2011, 'Learning to read in English: Comparing monolingual English and bilingual Zulu-English Grade 3 learners', South African Journal of Childhood Education 1(1), 1-18. https://doi.org/10.4102/sajce.v1i1.70

De Sousa, D.S., Greenop, K. \& Fry, J., 2011, 'The effects of phonological awareness of Zulu-speaking children learning to spell in English: A study of cross-language transfer', British Journal of Educational Psychology 80(Pt 4), 517-533. https://doi org/10.1348/000709910X496429

De Vos, M., Van der Merwe, K. \& Van der Mescht, C., 2015, 'A linguistic research programme for reading in African languages to underpin CAPS', Journal for Language Teaching 48(2), 148-177. https://doi.org/10.4314/jlt.v48i2.7

Diemer, M., Van der Merwe, K. \& De Vos, M., 2015, 'The development of phonological awareness literacy measures for IsiXhosa', Southern African Linguistics and Applied Language Studies 33(3), 325-341. https://doi.org/10.2989/16073614.20 15.110876

Diemer, M.N., 2015, 'The contributions of phonological awareness and naming speed to the reading fluency, accuracy, comprehension and spelling of Grade 3 isiXhosa readers', unpublished MA dissertation, Rhodes University, Grahamstown.

Ehri, L.C. \& Wilce, L.S., 1982, 'The salience of silent letters in children's memory for word spellings', Memory and Cognition 10, 155-166. https://doi.org/10.3758/ BF03209217

Fleisch, B., Pather, K. \& Motilal, G., 2017, 'The patterns and prevalence of monosyllabic three-letter-word spelling errors made by South African English First Additional Language learners', South African Journal of Childhood Education 7(1), 10. https:// doi.org/10.4102/sajce.v7i1.481

Golshan, M. \& Reigani P., 2015, 'Analysis spelling errors: Iranian female beginner learners of English', The Modern Journal of Applied Linguistics 7(2), 147-188.

Griffith, P.L., 1991, 'Phonemic awareness helps first graders invent spellings and third graders remember correct spellings', Journal of Reading Behavior 23(2), 215-233. https://doi.org/10.1080/10862969109547737

Gxilishe, S., Smouse, M.R., Xhalisa, T. \& De Villiers, J., 2009, 'Children's insensitivity to information from the target of agreement: The case of Xhosa', in $J$. Crawford et al. (eds.), Generative Approaches to Language Acquisition North America (GALANA), pp. 46-53, Cascadilla Proceedings Project, Somerville, MA. 
Howie, S., Combrinck, C., Roux, K., Tshele, M., Mokoena, G. \& McLeod Palane, N. 2017, PIRLS 2016 progress in international reading literacy study 2016: South African children's reading literacy achievement, Centre for Evaluation and Assessment, Pretoria, viewed 01 May 2019, from http://www.sajce.co.za.

Howie, S., Van Staden, S., Tshele, M., Dowse, C. \& Zimmerman, L., 2012, South African children's reading literacy achievement: Executive Summary 2011, CEA, University of Pretoria, Pretoria.

Howie, S., Venter, E., Van Staden, S., Zimmerman, L., Long, C., Scherman, V. et al.., 2008, Progress in International Reading Literacy Study 2006, Summary report. South African children's reading literacy achievement, Centre for Evaluation and Assessment, University of Pretoria, Pretoria.

Khider, A. \& Othman A., 2018, 'An investigation of the most common spelling errors in English writing committed by English-major male students: At the University of Tabuk', Journal of Education and Practice 9(1), 17-22.

Mann, V. \& Singson M., 2003, 'Linking morphological knowledge to English decoding ability: Large effects of little suffixes', in E.M.H Assink \& D. Sandra (eds.), Reading complex words. Neuropsychology and cognition, vol. 22, Springer, Boston, MA.

Mpiti, T., 2012, 'Nature of spelling errors of grade three isiXhosa background learners in English first additional language', unpublished doctoral dissertation, University of Fort Hare.

Nunes, T. \& Bryant, P., 2009, Children's reading and spelling. Beyond the first steps, Wiley-Blackwell, Hong Kong.

Nunes, T., Bryant, P. \& Bindman, M., 1997a, 'Learning to spell regular and irregula verbs', Reading and Writing: An Interdisciplinary Journal 9, 427-449. https://doi. org/10.1023/A:1007951213624

Park, C., 2011, 'The influence of L1 phonological and orthographic system in L2 spelling: A comparison of Korean learners of English and native speaking children', Unpublished PhD Dissertation, Ball State University Muncie.

Pijper, N.C., 2003, 'The phonological awareness, written spelling and oral reading of learners in an inclusive English-medium education setting', Master of Communication Pathology thesis, Faculty of Humanities, University of Pretoria, Pretoria.

Pretorius, E. \& Mokhwesana, M., 2009, 'Putting reading in Northern Sotho on track in the early years: Changing resources, expectations and practices in a High Poverty School', South African Journal of African Languages 1, 54-73. https://doi.org/10. 1080/02572117.2009.10587317

Pretorius, E.J. \& Spaull, N., 2016, 'Exploring relationships between oral reading fluency and reading comprehension amongst English second language readers in South Africa', Reading and Writing 29, 1449-1471. https//doi.org/10.1007/s11145-0169645-9

Probert, T., 2016, 'A comparative study of syllables and morphemes as literacy processing units in word recognition: IsiXhosa and Setswana', unpublished MA dissertation, Rhodes University, Grahamstown.

Probert, T. \& De Vos, M., 2016, 'Word recognition strategies amongst isiXhosa/English bilingual learners: The interaction of orthography and language of learning and teaching', Reading \& Writing 7(1), a84. https://doi.org/10.4102/rw.v7i1.84

Rees, S. \& Randera, A., 2019, 300 possible sight words for IsiXhosa - Foundation Phase, unpublished document.
Richards, S., 2001, 'The development of a formal diagnostic assessment tool for spelling in the foundation phase', Master of Education thesis, University of South Africa.

Sawyer D.J. \& Joyce M.T., 2006, 'Research in spelling: Implications for adult basic education', in J. Comings, B. Garner \& C. Smith (eds.), Annual review of adult learning and literacy, vol. 6, pp. 71-112, Lawrence Erlbaum Associates, Mahwah, NJ.

Schroeder, L., 2013, 'Teaching and assessing independent reading skills in multilingual African countries: Not as simple as $A B C^{\prime}$, in C. Benson \& K. Kosonen (eds.) Language issues in comparative education: Inclusive teaching and learning in nonLanguage issues in comparative education: Inclusive teaching and learning in n.)
dominant languages and cultures, $\mathrm{pp}$. 243-264, Sense Publishers, Rotterdam.

Schaefer, M. \& Kotzé, J., 2019, 'Early reading skills related to Grade 1 English Second Language literacy in rural South African schools', South African Journal of Childhood Education 9(1), a644. https://doi.org/10.4102/sajce.v9i1.644

Schaffler, D., 2007, 'The identification of spelling difficulties of learners in the foundation phase with Tswana as a medium of instruction', unpublished MA dissertation, North West University.

Spaull, N., 2013, South Africa's education crisis: The quality of education in South Africa 1994-2011, Centre for Development and Enterprise, Johannesburg.

Spaull, N., Pretorius, E. \& Mohohlwane, N., 2020, 'Investigating the comprehension iceberg: Developing empirical benchmarks for early-grade reading in agglutinating African languages', South African Journal of Childhood Education 10(1), e1-e14. https://doi.org/10.4102/sajce.v10i1.773

Templeton, S. \& Morris D., 2000, 'Spelling', in M.L. Kamil, P.B. Mosenthal, P.D. Pearson \& R. Barr (eds.), Handbook of reading research, vol. 3, pp. 525-543, Routledge, New York, NY.

Treiman, R., 1993, Beginning to spell: A study of first-grade children, Oxford University Press, New York.

Treiman, R., 2017, 'Learning to spell: Phonology and beyond', Cognitive Neuropsychology 34(3-4), 83-93. https://doi.org/10.1080/02643294.2017.1337630

Treiman, R. \& Cassar, M., 1996, 'Effects of morphology on children's spelling of final consonant clusters', Journal of Experimental Child Psychology 63(1), 141-170. https://doi.org/10.1006/jecp.1996.0045

Van der Berg, S., Spaull, N., Wills, G., Gustafsson, M. \& Kotzé, J., 2016, Identifying binding constraints in education, Department of Economics, University of Stellenbosch, Stellenbosch.

Vellutino, F.R., Fletcher, J.M., Snowling, M.J. \& Scanlon, D.M., 2004, 'Specific reading disability (dyslexia): What have we learned in the past four decades?' Journal of Child Psychology and Psychiatry 45(1), 2-40. https://doi.org/10.1046/ j.0021-9630.2003.00305.x

Wagner, R. \& Torgesen, J., 1987, 'The nature of phonological awareness and its casual role in the acquisition of reading skills', Psychological Bulletin 101(2), 192-212. https://doi.org/10.1037/0033-2909.101.2.192

Weinrich, B. \& Fay, E., 2007, 'Phonological awareness/literacy predictors of spelling abilities for first-grade children', Contemporary Issues in Communication Science and Disorders 39, 94-100. https://doi.org/1092-5171/07/3402-0094 


\section{Appendix 1}

\section{IsiXhosa spelling task stimuli}

TABLE 1-A1: Real words - Spelling task.

\begin{tabular}{|c|c|c|c|c|}
\hline Word & $\begin{array}{l}\text { English } \\
\text { translation }\end{array}$ & Length & Grapheme complexity & Frequency \\
\hline Oku & this & Disyllabic & No complexity & 88 \\
\hline Kwaye & and & Disyllabic & $\langle k w\rangle-$ consonant blend & 7 \\
\hline Lwakhe & his & Disyllabic & $\begin{array}{l}\langle\mid w\rangle-\text { consonant blend } \\
\langle k h\rangle-\text { aspirated digraph }\end{array}$ & 102 \\
\hline Phandle & outside & Disyllabic & $\begin{array}{l}\langle n d l\rangle \text { - consonant blend } \\
\langle p h\rangle-\text { aspirated digraph }\end{array}$ & 204 \\
\hline Amanzi & water & Trisyllabic & No complexity & 98 \\
\hline Kuqala & first & Trisyllabic & $\langle q\rangle-$ click & 199 \\
\hline Ixesha & time & Trisyllabic & $\begin{array}{l}\langle x\rangle-\text { click } \\
\langle s h\rangle-\text { aspirated digraph }\end{array}$ & 90 \\
\hline Namhlanje & today & Trisyllabic & $\begin{array}{l}\langle m h l\rangle \text { - consonant blend } \\
\langle n j\rangle-\text { consonant blend }\end{array}$ & 91 \\
\hline Amabali & stories & Quadrisyllabic & No complexity & 103 \\
\hline Umakhulu & grandmother & Quadreisyllabic & $\langle k h\rangle-$ aspirated digraph & 46 \\
\hline Amaqanda & eggs & Quadrisyllabic & $\begin{array}{l}\langle q\rangle-\text { click } \\
\langle n d\rangle-\text { consonant blend }\end{array}$ & 262 \\
\hline Ngaphakathi & inside & Quadrisyllabic & $\begin{array}{l}\langle k h\rangle \text { and }\langle t h\rangle-\text { aspirated } \\
\text { digraph } \\
\langle n g\rangle-\text { diagraph }\end{array}$ & 175 \\
\hline
\end{tabular}

Note: The documents used to create the list were all documents used in Foundation Phase classrooms in South Africa. These include the Molteno Vula Bula books, Nal'iBali supplements and Departmental workbooks.

TABLE 2-A1: Pseudoword spelling task.

\begin{tabular}{|c|c|c|}
\hline Word & Length & Grapheme complexity \\
\hline Tuza & Disyllabic & No complexity \\
\hline Ngela & Disyllabic & $\langle n g\rangle-$ consonant digraph \\
\hline Lwesha & Disyllabic & $\begin{array}{l}\langle\mid w\rangle-\text { consonant blend } \\
\langle s h\rangle-\text { aspirated digraph }\end{array}$ \\
\hline Incwa & Disyllabic & $\langle n c w\rangle-$ consonant blend and click \\
\hline Tshafiba & Trisyllabic & $\langle t s h\rangle$-trigraph \\
\hline Ndlashaza & Trisyllabic & $\begin{array}{l}\langle n d l\rangle-\text { consonant blend } \\
\langle s h\rangle-\text { aspirated digraph }\end{array}$ \\
\hline Ingxembo & Trisyllabic & $\begin{array}{l}\langle n g x\rangle-\text { consonant blend } \\
\langle m b\rangle-\text { nasal consonant blend }\end{array}$ \\
\hline Izasiso & Trisyllabic & No complexity \\
\hline Nokunene & Quadrisyllabic & No complexity \\
\hline Nokhube & Quadrisyllabic & $\langle k h\rangle-$ aspirated digraph \\
\hline Inkweseva & Quadrisyllabic & $\langle n k w\rangle-$ consonant blend \\
\hline Khuqahleyo & Quadrisyllabic & $\begin{array}{l}\langle k h\rangle-\text { aspirated digraph } \\
\langle h l\rangle \text { - digraph } \\
\langle q\rangle \text { - click }\end{array}$ \\
\hline
\end{tabular}

